\title{
HEMATOLOGICAL PROFILE IN PATIENTS OF CHRONIC KIDNEY DISEASE WITH ITS SEVERITY IN A TERTIARY CARE HOSPITAL, NORTH ODISHA
}

\author{
BIBHU PRASAD BEHERA* \\ Department of Internal Medicine, Saheed Laxman Nayak Medical College and Hospital, Koraput, Odisha, India. \\ Email: drbibhu1111@yahoo.com
}

Received: 01 May 2020, Revised and Accepted: 10 June 2020

\begin{abstract}
Objective: Efforts can be made to normalize the hematological parameters and slow the progress of the disease so that the morbidity and mortality in these patients with chronic kidney disease could be effectively reduced.

Methods: The observational study was carried out in the Department of General Medicine, Pandit Raghunath Murmu Medical College Hospital, Baripada, between May 2018 and January 2019. Two hundred seventy patients of chronic kidney disease (CKD) above 15 years of age, satisfying the inclusion and exclusion criteria, were included in the study.

Results: In our study, $179(66.30 \%)$ were male, and 91 (33.70\%) were female with M:F of 1.97:1. The average age of the patients in the study was $55.72 \pm 12.77$ years. About $42.59 \%$ (115) of the patients were between 46 and 60 years of age. About 35.56\% of CKD cases had determined etiology and, $64.44 \%$ of cases had unknown etiology. Hemoglobin, RBC, and packed cell volume were significantly lower in the patients with CKD compared to the controls ( $\mathrm{p}=0.0001)$, and RDW was considerably higher in the patients with CKD compared to the controls ( $\mathrm{p}=0.0001)$. Microcytic anemia was the most prevalent type of anemia. There was a hugely significant association between the prevalence of thrombocytopenia and the severity of CKD $(\mathrm{p}=0.006)$.
\end{abstract}

Conclusion: This study concluded that patients with CKD show abnormal hematological parameters. Evaluation of hematological parameters in these patients helps in classifying the type of anemia, aids in choosing the correct treatment modalities, and decreases mortality.

Keywords: Chronic kidney disease, Anemia, Hemoglobin, Red blood count, Thrombocytopenia.

(C) 2020 The Authors. Published by Innovare Academic Sciences Pvt Ltd. This is an open access article under the CC BY license (http://creativecommons. org/licenses/by/4. 0/) DOI: http://dx.doi.org/10.22159/ajpcr.2020.v13i8.38101

\section{INTRODUCTION}

Chronic kidney disease (CKD) encompasses a spectrum of different pathophysiologic processes coupled with abnormal kidney function and a progressive decrease in glomerular filtration rate (GFR) [1]. CKD is a universal public health problem, both for the number of patients and the cost of treatment involved, especially in developing countries like India. Internationally, CKD is the $12^{\text {th }}$ cause of death and the $17^{\text {th }}$ cause of disability, respectively [2] with a prevalence of $8-16 \%$ [3]. About $6 \%$ of the adult populations have CKD Stages 1 and 2, and $4.5 \%$ have CKD Stages 3 and 4 (United States population data) [1].

As stated by the National Kidney Foundation in India, renal diseases ranked $3^{\text {rd }}$ among the life-threatening diseases after cancer and heart disease, with about 2 Lakh persons landing into terminal renal failure annually and millions more suffering from lesser forms of renal diseases [4].

The prevalence is high in India, with 229/million population suffering from end-stage renal disease (ESRD) [5]. Community-based studies planned to detect stage 3 CKD or worse show prevalence between $0.16 \%$ and $0.79 \%$; with the actual incidence of CKD is higher than the reported number [6-8]. The ESRD incidences have been reported to be 160-232 per million populations (pmp) [5,6] with a projected ESRD prevalence of 785-870 pmp [5,9]. In summary, from the database of CKD registry of India, the yearly incidence of ESRD in India is approximately 150-200 pmp with diabetes mellitus as an important cause of CKD in approximately $30-40 \%$ of the cases [10].

There is a proportional increase in the prevalence and severity of hematological impairment with increasing severity of kidney dysfunction. Studies have revealed that anemia begins to noticeable when GFR falls below $60 \mathrm{ml} / \mathrm{min} / 1.73 \mathrm{~m}^{2}$ (Stage III) [11]. Accordingly, the prevalence of anemia ranges from about $1 \%$ in stage 2 of CKD to almost $100 \%$ in ESRD patients [12].

Pathophysiologically, anemia is determined by multiple factors in CKD patients [13]. A kidney is a crucial site for EPO production, contributing $80-90 \%$ of total EPO in circulation (rest $10-20 \%$ produced in the liver). The most significant and crucial factor are the deficient production of erythropoietin (EPO) by the damaged kidneys [14]. Other important factors contributing to the development of anemia in CKD include nutritional deficiencies (Iron, folate, or Vitamin b12), increased blood loss, systemic and chronic inflammatory state, hyperparathyroidism, and shortened red cell survival by uremic toxins and drugs [15].

A load of cardiovascular disease in CKD is further augmented in the coexistence of anemia, particularly in high-risk populations, together with a higher risk of progression of CKD to ESRD and repeated hospitalization $[16,17]$.

Anemia in CKD is associated with disease progression, cardiovascular comorbidities, cognitive impairment, sleep disorder, and higher mortality $[18,19]$. Direct health-care costs are on the rise in CKD patients with anemia than in those without [20]. Among CKD patients, at all levels of GFR, anemia portends a poor prognosis and is associated with increased mortality compared with those individuals with preserved hemoglobin $(\mathrm{Hb})[21]$.

We come across a large number of patients with CKD with abnormal hematological parameters in our institution of PRM Medical College, Baripada. As these being unpublished facts, we want to carry out a study, first of this type in our new medical college, to assess the array of 
hematological abnormalities in our patients with predialysis CKD and associated factors.

\section{METHODS}

The observational study was conducted in the Department of General Medicine, Pandit Raghunath Murmu Medical College Hospital, Baripada. The CKD patients who had attended the department of general medicine OPD and who were admitted to the department of general medicine, PRM MCH, Baripada between May 2018 and January 2019 were enrolled in our study.

\section{Inclusion criteria}

- All patients of CKD above 15 years of age, satisfying the following criteria, were included in the study. Criteria for diagnosis of CKD were as given by - National Kidney Foundation: K/DOQI clinical practice guidelines for CKD: Evaluation, classification, and stratification [22].

CKD is defined as the presence, for at least 3 months, of evidence of kidney damage with an abnormal GFR or alternatively, by a GFR $<60 \mathrm{ml} / \mathrm{min} / 1.73 \mathrm{~m}^{2} \mathrm{BSA}$ [22]

Kidney damage is evidenced by:

- Proteinuria $>300 \mathrm{mg} /$ day OR

- Pathological abnormality found in histopathological study OR

- Renal imaging study (USG) showing bilateral contracted kidneys $<9.0 \mathrm{~cm}$ with thinned parenchyma and reduced corticomedullary differentiation.

\section{Exclusion criteria}

The following criteria were excluded from the study:

- Patients aged below 15 years of age

- Patients on hemodialysis

- Pregnant and lactating women

- Aplastic anemia

- Known hematological malignancy causing secondary renal failure

- History of blood transfusion during the past 3 months

- History of erythropoietin therapy during the past 3 months

- Patients suffering from recent hemorrhagic episodes were excluded from the study.

Two hundred seventy CKD patients were included in the study, divided into three groups.

- Group A $\rightarrow$ Mild CKD (n=120) (S. Creatinine $=1.5-3.0 \mathrm{mg} / \mathrm{dl}$ )

- Group B $\rightarrow$ Moderate CKD (n=91) (S. Creatinine =3-6.0 mg/dl)

- Group C $\rightarrow$ Severe CKD $(\mathrm{n}=59)$ (S. Creatinine $>6.0 \mathrm{mg} / \mathrm{dl})$

\section{Investigations}

After due consideration into inclusion and exclusion criteria, detailed history and clinical examination were undertaken in all patients. All patients had undergone thorough laboratory investigations such as complete blood counts (Sysmex XS-800i), urine analysis, blood sugar, serum urea, and creatinine. Ultrasonography of the abdomen was done on every patient. The CKD epidemiology collaboration equation, 2009, was used to calculate e-GFR. e-GFR was graded G1, G2, G3a, G3b, G4, and G5 as indicated by the KDIGO 2012 guidelines [1]. Forty healthy persons were taken as controls.

The World Health Organization defined anemia as $\mathrm{Hb}$ concentration $<12 \mathrm{~g} / \mathrm{dl}$ (females), <13 g/dl (males) classifying the severity of anemia as mild anemia ( $\mathrm{Hb}$ concentration between $11-12.9 \mathrm{~g} / \mathrm{dl}$ for males and $11-11.9 \mathrm{~g} / \mathrm{dl}$ for females); moderate anemia ( $\mathrm{Hb}$ concentration between 8 and $10.9 \mathrm{~g} / \mathrm{dl}$ ), and severe anemia (Hb concentration $<8 \mathrm{~g} / \mathrm{dl}$ ) [23]. Thrombocytopenia was defined with a value of $<150 \times 10^{3} / \mu$ l.

\section{Statistical analysis}

The statistical analysis was done using the Statistical Package for the Social Sciences version 21.0. The demographic features of the study population were explained using univariate analysis. Discrete variables were described as frequency and percentages. Continuous variables were presented as means and standard deviation (SD) for unpaired data; the Student's t-test was used to compare mean values (for two groups). Pearson's correlation was used to establish the association between eGFR and other variables. A Chi-square test was used to determine the significant associations between categorical variables. $\mathrm{p}<0.05$ was considered statistically significant* and $<0.01$ was considered as statistically hugely significant**.

\section{RESULTS}

During the study period, 270 CKD patients above 15 years of age, satisfying the inclusion and exclusion criteria were included in the study. All the cases were studied for the clinical presentation, risk factors, and laboratory parameters.

Out of 270 patients, $179(66.30 \%)$ were male and $91(33.70 \%)$ were female with M:F of 1.97:1 (Fig. 1). The average age of the patients in this study was 55.72 \pm 12.77 years. The average age of the male and female patients in the study was $55.63 \pm 13.24$ and $55.89 \pm 11.84$ years, respectively. The age range was from 20 to 95 years.

Fig. 2 shows that $42.59 \%$ (115) of the patients were between 46 and 60 years of age, and $26.30 \%$ (71) of the patients were between 61 and 75 years of age.

Fig. 3 shows that $35.56 \%$ CKD cases had determined etiology such as hypertension $(32.22 \%)$, diabetes $(4.07 \%)$, adult polycystic kidney disease $(1.48 \%)$, obstructive nephropathy $(1.11 \%)$, and medullary sponge kidney $(0.37 \%)$; and rest of the $64.44 \%$ cases had unknown etiology.

Table 1 shows $21.85 \%$ (59), $42.59 \%$ (115), and $35.56 \%$ (96) of the patients in our study group belong to stage 3 , stage 4 , and stage 5 CKD, respectively.

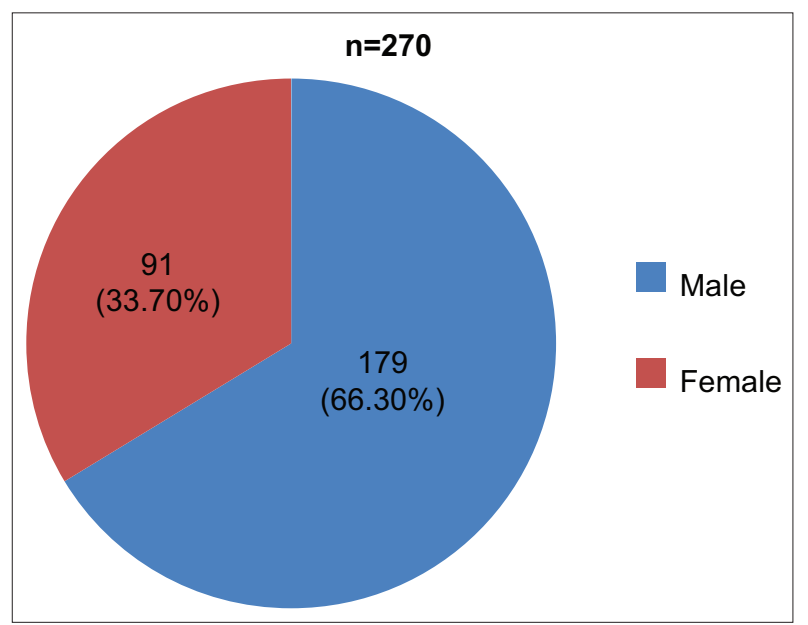

Fig. 1: Gender distribution

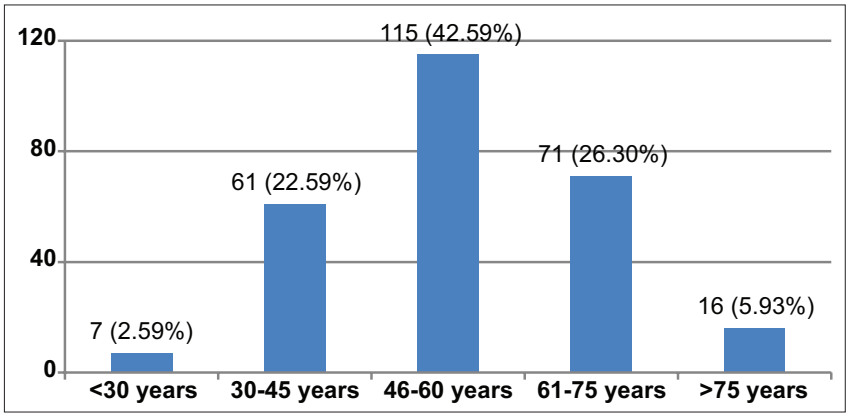

Fig. 2: Age distribution 
Fig. 4 show 120 (44.44\%) patients belong to mild CKD (Group-A), 91 $(33.70 \%)$ patients belong to moderate CKD (Group-B), and $59(21.85 \%)$ patients belong to severe CKD (Group-C) in our study group.

Table 2 shows the comparisons between hematologic indices of CKD patients and healthy controls. $\mathrm{Hb}, \mathrm{RBC}$, and packed cell volume were significantly lower in the patients with CKD compared to the controls $(\mathrm{p}=0.0001)$, and RDW was significantly higher in the patients with CKD compared to the controls ( $\mathrm{p}=0.0001$ ).

Table 3 shows the correlation coefficient of eGFR with different variables in CKD patients. Negative Pearson's correlation coefficient value indicate age, the level of systolic BP, diastolic BP, blood urea, serum creatinine, MCV, MCH, MCHC, and RDW increase with the decline of GFR and positive Pearson's correlation coefficient value indicate the level of hemoglobin, RBC, PCV, and TPC decrease with the decline of GFR. On correlating eGFR with various parameters, statistical significance was observed with systolic blood pressure $(r=-0.191, * * p=0.0016)$, diastolic blood pressure $\left(r=-0.140,{ }^{*} \mathrm{p}=0.0213\right)$, B. Urea $(\mathrm{r}=-0.729$, $\left.{ }^{* *} \mathrm{p}=0.00001\right)$, S. Creatinine $(\mathrm{r}=-0.787, * * \mathrm{p}=0.00001)$, hemoglobin $\left(\mathrm{r}=0.290,{ }^{* *} \mathrm{p}=0.00001\right), \mathrm{RBC}\left(\mathrm{r}=0.342,{ }^{* *} \mathrm{p}=0.00001\right), \mathrm{PCV}(\mathrm{r}=0.315$, $\left.{ }^{* *} \mathrm{p}=0.00001\right)$, and $\mathrm{MCH}\left(\mathrm{r}=-0.150,{ }^{*} \mathrm{p}=0.0136\right)$.

Table 4 shows the prevalence of anemia increased from $96.61 \%$ in Stage $3,97.39 \%$ in Stage 4, and 100\% in Stage 5 CKD, respectively. There was a hugely significant association between the severity of anemia and the stage of CKD (** $\mathrm{p}=0.000032)$

Table 5 shows that $98.15 \%$ (265 cases) of the study population had anemia. The prevalence of anemia increased from $96.67 \%$ in mild CKD, $98.90 \%$ in moderate CKD, and $100 \%$ in severe CKD, respectively. There was a hugely significant association between the severity of anemia and the severity of CKD $\left({ }^{* *} \mathrm{p}=0.00001\right)$.

Table 6 shows that $80.37 \%$ (217) of CKD patients had microcytic anemia. Normocytic anemia was seen in $17.41 \%$ (47) of CKD patients and macrocytic anemia was seen in $0.37 \%$ (1) of CKD patients. There was no significant association between the type of anemia (PCV) and the severity of CKD.

Table 7 shows that $38.52 \%$ (104 cases) of the study population had thrombocytopenia. The prevalence of thrombocytopenia increased from $30.83 \%$ in mild CKD, 35.16\% in moderate CKD, and 59.32\%

Table 1: Chronic kidney disease stage based on GFR

\begin{tabular}{lll}
\hline Stage of chronic kidney disease (ml/min) & $\mathbf{n}$ & $\mathbf{f ~ ( \% )}$ \\
\hline Stage 1 (GFR > 90) & 0 & 0.00 \\
Stage 2 (GFR 60-89) & 0 & 0.00 \\
Stage 3a (GFR 45-59) & 6 & 2.22 \\
Stage 3b (GFR 30-44) & 53 & 19.63 \\
Stage 4 (GFR 15-29) & 115 & 42.59 \\
Stage 5 (GFR <15) & 96 & 35.56 \\
Total & 270 & 100 \\
\hline
\end{tabular}

in severe CKD. There was a hugely significant association between the prevalence of thrombocytopenia and the severity of CKD $\left({ }^{* *} \mathrm{p}=0.006\right)$.

Table 8 show that there was a hugely significant association between blood urea and serum creatinine level with mild, moderate, and severe CKD $(* * p=0.0001)$. There was decrease in level of hemoglobin, RBC, and PCV with severity of disease with hugely significant association between mild to severe and moderate to severe CKD $\left({ }^{* *} \mathrm{p}=0.0001\right)$.

\section{DISCUSSION}

In our study, out of 270 patients, 179 (66.30\%) were male, and 91 $(33.70 \%)$ were female with M:F of 1.97:1. As per the patients enrolled in the database of "The Indian CKD Registry," a voluntary reporting body of CKD patient's data, initiated in June 2005, 70\% of them were males [10]. The patients in the study had an average age of $55.72 \pm 12.77$ years, ranging from 20 to 95 years. Most of the patients, $74.82 \%$ were above 45 years of age, but still, $25.18 \%$ of the CKD patients were below 45 years of age, which was significant in number. According to Suhnggwon Kim et al. 2009, the average age of the CKD patient was with mean 50.5 years and a SD of 11.1 years [24].

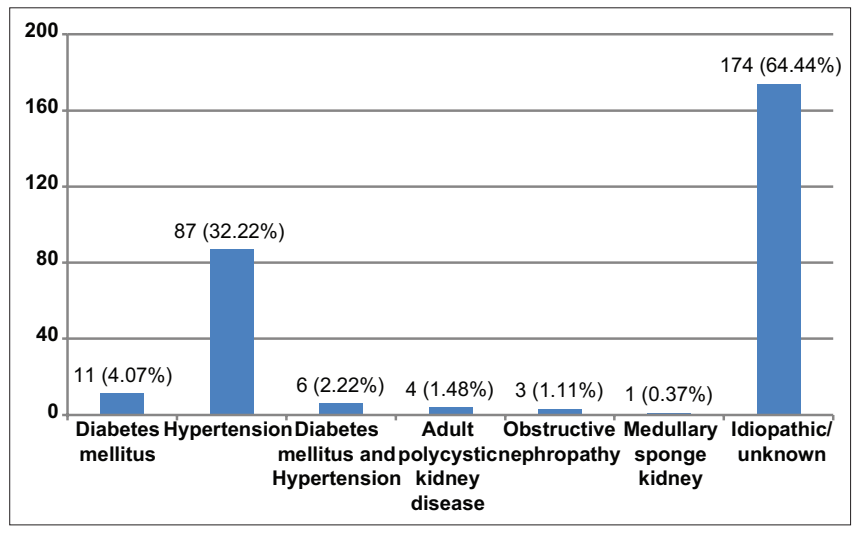

Fig. 3: Etiology of chronic kidney disease

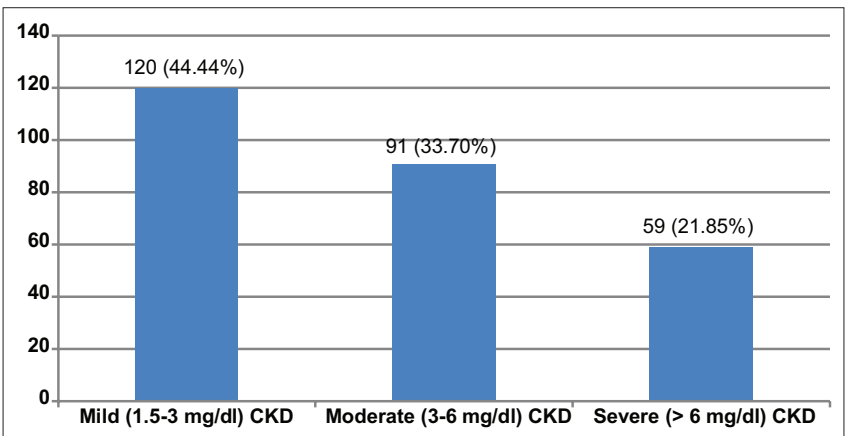

Fig. 4: Creatinine levels with severity of chronic kidney disease

Table 2: Hematologic indices of CKD patients and controls

\begin{tabular}{|c|c|c|c|}
\hline Indices & $\begin{array}{l}\text { CKD patients }(n=270) \\
(\text { mean } \pm S D)\end{array}$ & $\begin{array}{l}\text { Controls }(n=40) \\
(\text { mean } \pm S D)\end{array}$ & p-value \\
\hline Hemoglobin (g/dl) & $7.76 \pm 2.50$ & $13.20 \pm 1.03$ & $0.0001^{* *}$ \\
\hline Red blood count $\left(\mathrm{M}=4.7-6.1\right.$ million $/ \mathrm{mm}^{3}$ and $\mathrm{F}=4.2-5.4$ million $/ \mathrm{mm}^{3}$ ) & $3.27 \pm 1.03$ & $5.64 \pm 0.65$ & $0.0001^{* *}$ \\
\hline Mean corpuscular volume (80-100 fL) & $70.53 \pm 9.42$ & $71.99 \pm 8.67$ & 0.3563 \\
\hline Packed cell volume/hematocrit $(\mathrm{M}=40.7-50.3 \%$ and $\mathrm{F}=36.1-44.3 \%)$ & $22.95 \pm 7.53$ & $40.13 \pm 3.06$ & $0.0001^{* *}$ \\
\hline Mean corpuscular hemoglobin (27-31 pg) & $23.61 \pm 3.06$ & $23.56 \pm 3.43$ & 0.9244 \\
\hline Mean corpuscular hemoglobin concentration (33.4-35.5 g/dl) & $33.51 \pm 4.74$ & $32.86 \pm 1.49$ & 0.3905 \\
\hline Total platelet count (1.5-4.5 lakh per ml) & $1.87 \pm 0.89$ & $1.85 \pm 0.47$ & 0.8894 \\
\hline
\end{tabular}

*Significance at $p<0.05,{ }^{* *}$ hugely significance at $p<0.01$ 
We revealed that $35.56 \%$ CKD cases had determined etiology such as hypertension $(32.22 \%)$, diabetes $(4.07 \%)$, adult polycystic kidney disease $(1.48 \%)$, obstructive nephropathy (1.11\%), and medullary

Table 3: Correlation coefficient of eGFR with different variables in CKD patients

\begin{tabular}{lll}
\hline Variables & $\begin{array}{l}\text { Pearson correlation } \\
\text { coefficient (r) }\end{array}$ & p-value \\
\hline Age & -0.002 & 0.9739 \\
Systolic BP & -0.191 & $0.0016^{* *}$ \\
Diastolic BP & -0.140 & $0.0213^{*}$ \\
Blood urea & -0.729 & $0.00001^{* *}$ \\
Serum creatinine & -0.787 & $0.00001^{* *}$ \\
Hemoglobin & 0.290 & $0.00001^{* *}$ \\
RBC & 0.342 & $0.00001^{* *}$ \\
MCV & -0.030 & 0.6235 \\
PCV & 0.315 & $0.00001^{* *}$ \\
MCH & -0.150 & $0.0136^{*}$ \\
MCHC & -0.080 & 0.1900 \\
RDW & -0.062 & 0.3101 \\
TPC & 0.096 & 0.1155 \\
\hline
\end{tabular}

*Significance at $p<0.05,{ }^{* *}$ hugely significance at $p<0.01$ sponge kidney $(0.37 \%)$; and rest of the $64.44 \%$ cases had unknown etiology; which is an important finding. CKD of unknown etiology has also been documented from other parts of South Asia and among South Asians living in the UK [25].

In our study, $\mathrm{Hb} \%$ ranged from 2.8 to $14.3 \mathrm{~g} / \mathrm{dl}$, with a mean of $7.76 \pm 2.50 \mathrm{~g} / \mathrm{dl}$. The RBC count ranged from 1.19 to $5.8 \times 10^{3} / \mu \mathrm{l}$, with a mean of $3.27 \pm 1.03$. Hematocrit ranged from $7.6 \%$ to $43.5 \%$, with a mean of $28.48 \% \pm 7.8 \%$. These parameters are quite similar to the findings in Shastry et al. study [26]. In Shastry et al. study, $\mathrm{Hb}$ level ranged from 3.6 to $14.2 \mathrm{~g} / \mathrm{dl}$ with a mean of $9.31 \pm 0.52 \mathrm{~g} /$ $\mathrm{dl}$, the RBC count ranged from 1.29 to $4.22 \times 10^{3} / \mu \mathrm{l}$, with a mean of $3.29 \pm 0.79$ and hematocrit ranged from $11.6 \%$ to $42 \%$ with a mean of $28.48 \pm 7.8 \%$. Our study recognized that $\mathrm{Hb}, \mathrm{RBC}$, and packed cell volume were significantly lower in the patients with CKD compared to the controls $(p=0.0001)$, which was also revealed in Shastry et al. study. We found positive Pearson's correlation coefficient value, which indicates the level of $\mathrm{Hb}, \mathrm{RBC}$, and PCV decrease with the decline of eGFR, with statistical significance $(p=0.00001)$. We revealed in our study that there was a decline in the level of $\mathrm{Hb}$, RBC, and PCV with the severity of disease with a hugely significant association between mild to severe and moderate to severe CKD $(\mathrm{p}=0.0001)$. Singh et al. [27], Poudel et al. [28], Bueno and Frizzo

Table 4: Associations between the severity of anemia and stage of CKD (with e-GFR)

\begin{tabular}{|c|c|c|c|c|c|c|c|}
\hline \multirow[t]{2}{*}{ Severity of anemia } & \multicolumn{2}{|c|}{ CKD Stage 3} & \multicolumn{2}{|c|}{ CKD Stage 4} & \multicolumn{2}{|c|}{ CKD Stage 5} & \multirow[t]{2}{*}{ Test statistic } \\
\hline & $\mathbf{n}$ & $f(\%)$ & $\mathbf{n}$ & f (\%) & $\mathbf{n}$ & $f(\%)$ & \\
\hline Mild (11-12.9 g/dl in males) and (11-11.9 g/dl in females) & 9 & 15.79 & 13 & 11.61 & 6 & 6.25 & $\begin{array}{l}\chi^{2}=25.9988 \\
\mathrm{df}=4\end{array}$ \\
\hline Moderate $(8-10.9 \mathrm{~g} / \mathrm{dl})$ & 20 & 35.09 & 55 & 49.11 & 20 & 20.83 & $\mathrm{p}=0.000032^{* *}$ \\
\hline Severe $(<8 \mathrm{~g} / \mathrm{dl})$ & 28 & 49.12 & 44 & 39.29 & 70 & 72.92 & \\
\hline
\end{tabular}

*Significance at $p<0.05,{ }^{* *}$ hugely significance at $p<0.01$

Table 5: Associations between the severity of anemia and the severity of CKD (with serum creatinine)

\begin{tabular}{|c|c|c|c|c|c|c|c|}
\hline \multirow[t]{2}{*}{ Severity of anemia } & \multicolumn{2}{|c|}{ Mild (n=120) } & \multicolumn{2}{|c|}{ Moderate $(n=91)$} & \multicolumn{2}{|c|}{ Severe $(n=59)$} & \multirow[t]{2}{*}{ Test statistic } \\
\hline & $\mathbf{n}$ & $f(\%)$ & $\mathbf{n}$ & f (\%) & $\mathbf{n}$ & f (\%) & \\
\hline Mild (11-12.9 g/dl in males) and (11-11.9 g/dl in females) & 17 & 14.17 & 8 & 8.79 & 3 & 5.08 & $\begin{array}{l}\chi^{2}=35.1204 \\
d f=4\end{array}$ \\
\hline Moderate $(8-10.9 \mathrm{~g} / \mathrm{dl})$ & 49 & 40.83 & 41 & 45.05 & 5 & 8.47 & $\mathrm{p}=0.00001^{* *}$ \\
\hline Severe $(<8 \mathrm{~g} / \mathrm{dl})$ & 50 & 41.67 & 41 & 45.05 & 51 & 86.44 & \\
\hline
\end{tabular}

*Significance at $p<0.05,{ }^{* *}$ hugely significance at $p<0.01$

Table 6: Associations between types of anemia and severity of CKD

\begin{tabular}{|c|c|c|c|c|c|c|c|}
\hline \multirow[t]{2}{*}{$\operatorname{MCV}$ (fL) } & \multicolumn{2}{|c|}{ Mild (n=120) } & \multicolumn{2}{|c|}{ Moderate $(n=91)$} & \multicolumn{2}{|c|}{ Severe $(n=59)$} & \multirow[t]{2}{*}{ Test statistic } \\
\hline & $\mathbf{n}$ & $f(\%)$ & $\mathbf{n}$ & $f(\%)$ & $\mathbf{n}$ & f (\%) & \\
\hline Microcytic $(<80 \mathrm{fL})$ & 96 & 80.00 & 74 & 81.32 & 47 & 79.66 & $\chi^{2}=0.0786$ \\
\hline Normocytic (80-100 fL) & 20 & 16.67 & 16 & 17.58 & 11 & 18.64 & $\mathrm{df}=2$ \\
\hline Macrocytic (>100 fL) & 0 & 0.00 & 0 & 0.00 & 1 & 1.69 & $p=0.961459$ \\
\hline
\end{tabular}

Table 7: Associations between thrombocytopenia and severity of CKD

\begin{tabular}{|c|c|c|c|c|c|c|c|c|c|}
\hline \multirow[t]{2}{*}{ Platelet count (lakh/ml) } & \multirow[t]{2}{*}{ Total } & \multirow[t]{2}{*}{ f (\%) } & \multicolumn{2}{|c|}{ Mild (n=120) } & \multicolumn{2}{|c|}{ Moderate $(n=91)$} & \multicolumn{2}{|c|}{ Severe $(n=59)$} & \multirow[t]{2}{*}{ Test statistic } \\
\hline & & & $\mathbf{n}$ & $f(\%)$ & $\mathbf{n}$ & f (\%) & $\mathbf{n}$ & f (\%) & \\
\hline$<1.5$ & 104 & 38.52 & 37 & 30.83 & 32 & 35.16 & 35 & 59.32 & $\begin{array}{l}\chi^{2}=14.3966 \\
d f=4\end{array}$ \\
\hline $1.5-4.5$ & 159 & 58.89 & 79 & 65.83 & 57 & 62.64 & 23 & 38.98 & $\mathrm{p}=0.006131^{* *}$ \\
\hline \multirow[t]{2}{*}{$>4.5$} & 7 & 2.59 & 4 & 3.33 & 2 & 2.20 & 1 & 1.69 & \\
\hline & 270 & 100.00 & 120 & 100 & 91 & 100 & 59 & 100 & \\
\hline
\end{tabular}

*Significance at $p<0.05,{ }^{* *}$ hugely significance at $p<0.01$ 
Table 8: Associations of hematologic indices with the severity of CKD patients

\begin{tabular}{|c|c|c|c|c|c|c|}
\hline Hematologic indices & Mild (A) $($ Mean \pm SD) & $\begin{array}{l}\text { Moderate (B) } \\
(\text { Mean } \pm \text { SD) }\end{array}$ & $\begin{array}{l}\text { Severe (C) } \\
(\text { Mean } \pm \text { SD) }\end{array}$ & $\begin{array}{l}\text { p-value } \\
\text { (A vs. B) }\end{array}$ & $\begin{array}{l}\text { p-value } \\
\text { (A vs. C) }\end{array}$ & $\begin{array}{l}\text { p-value } \\
\text { (B vs. C) }\end{array}$ \\
\hline Blood urea & $66.61 \pm 22.34$ & $111.49 \pm 32.53$ & $191.79 \pm 62.02$ & $0.0001^{* *}$ & $0.0001^{* *}$ & $0.0001^{* *}$ \\
\hline Serum creatinine & $2.24 \pm 0.41$ & $3.98 \pm 0.78$ & $8.79 \pm 2.35$ & $0.0001^{* *}$ & $0.0001^{* *}$ & $0.0001^{* *}$ \\
\hline Hemoglobin & $8.43 \pm 2.38$ & $7.96 \pm 2.46$ & $6.10 \pm 2.04$ & 0.1629 & $0.0001^{* *}$ & $0.0001^{* *}$ \\
\hline $\mathrm{RBC}$ & $3.59 \pm 1.01$ & $3.33 \pm 0.97$ & $2.54 \pm 0.81$ & 0.0610 & $0.0001^{* *}$ & $0.0001^{* *}$ \\
\hline MCV & $70.65 \pm 9.63$ & $70.43 \pm 9.30$ & $70.44 \pm 9.36$ & 0.8677 & 0.8901 & 0.9949 \\
\hline PCV & $25.21 \pm 7.46$ & $23.30 \pm 7.04$ & $17.81 \pm 5.85$ & 0.0606 & $0.0001^{* *}$ & $0.0001^{* *}$ \\
\hline $\mathrm{MCHC}$ & $33.25 \pm 4.62$ & $33.52 \pm 4.58$ & $34.04 \pm 5.27$ & 0.6735 & 0.3063 & 0.5233 \\
\hline RDW & $16.29 \pm 2.38$ & $16.20 \pm 2.61$ & $16.61 \pm 2.42$ & 0.7944 & 0.4015 & 0.3352 \\
\hline TPC & $1.98 \pm 0.88$ & $1.82 \pm 0.86$ & $1.72 \pm 0.946$ & 0.1880 & 0.0720 & 0.5055 \\
\hline
\end{tabular}

*Significance at $p<0.05,{ }^{* *}$ hugely significance at $p<0.01$

[29], and De Francisco et al. [30], and Elsayed and Azab [31] studies also showed decreased $\mathrm{Hb}$, low RBC counts, and hematocrit values associated with CKD patients. It has been proposed that in CKD, impaired production of EPO is the foremost reason for the decline in $\mathrm{RBC}$ count, $\mathrm{Hb}$ concentration, hematocrit, and platelet count with other related factors such as increase hemolysis, suppression of bone marrow erythropoiesis, hematuria, and gastrointestinal blood loss playing their parts in it.

Anemia was observed in $98.15 \%$ (265 cases) of the study population with a hugely significant association between the severity of anemia and the severity of CKD $\left({ }^{* *} \mathrm{p}=0.00001\right)$; comparable to the figures found in studies by Shittu et al. and Arun et al., who reported the prevalence of anemia to be $94 \%$ and $98 \%$, respectively $[32,33]$. The association of the severity of anemia with the stage of CKD and the severity of CKD $\left.{ }^{* *} \mathrm{p}=0.000032\right)$ were hugely significant, which was similar to Suresh et al. study [34]. Microcytic anemia was seen in $80.37 \%$ (217) of CKD patients. In India, iron deficiency anemia is widespread. Talwar et al. study reported microcytic hypochromic anemia as the predominant type of anemia observed in CKD patients [35]. About 38.52\% (104 cases) of the study population had thrombocytopenia. The level of total platelet count was declined, though not statistically significant, with the progression of the stage of CKD. There was a hugely significant association between the prevalence of thrombocytopenia and the severity of CKD $\left({ }^{* *} \mathrm{p}=0.006\right)$. Arun et al. study recorded thrombocytopenia in $29 \%$ of the patients with CKD, of which 19 patients had ESRD [33].

\section{CONCLUSION}

Our study accomplished that patients with CKD show abnormal hematological parameters; there is a correlation between the progression of CKD and reduction in $\mathrm{Hb}$, red blood count, hematocrit, and platelet count. Anemia is a significant cause of morbidity in patients with CKD worsening with the stage of the disease. The most frequent type of anemia is microcytic hypochromic anemia due to iron deficiency. Measurement of $\mathrm{Hb}$ and RBC parameters in patients with CKD helps in classifying the type of anemia, aids in choosing the correct management modalities, and decreasing mortality. Future studies should be made to know the undetermined etiology of CKD in this part of ODISHA. However, timely identification and rectification of anemia in patients with CKD are recommended.

\section{ACKNOWLEDGMENTS}

The authors would like to thank Dr. Partha S. Mohanty, Dr. Arunima Pattanaik, Dr. Sambit Parida, Dr. Soumyasmruti Parida, Nibedita Mantry, Swarnalata Samal, Saraswati Sahoo, Rubina Soren, Mamata Nayak, Suchismita Patra, staffs of the Department of Medicine, PRM MCH, Baripada, Odisha, India, for their cooperation in the collection of data.

\section{AUTHOR'S CONTRIBUTIONS}

Dr. Bibhu Prasad Behera, Assistant Professor in Medicine, Department of Internal Medicine, Saheed Laxman Nayak Medical College and Hospital,
Koraput, ODISHA is the primary investigator and the corresponding author. Dr. Bibhu Prasad Behera made the design of the study, data collection, redaction of the manuscript, statistic study, analysis of data, and data interpretation.

\section{CONFLICTS OF INTEREST}

None.

\section{AUTHORS' FUNDING}

No funding resource.

\section{ETHICAL APPROVAL}

It is not required.

\section{REFERENCES}

1. Bargman JM, Skorecki K. Chronic Kidney Disease in Harrison's Principles of Internal Medicine. 20 $0^{\text {th }}$ ed., Vol. 2. New York: McGrawHill Publication; 2018. p. 2111-21.

2. Veerappan I, Abraham G. Chronic kidney disease: Current status, challenges and management in India. In Medicine Update. Mumbai: Association of Physicians of India; 2013. p. 593-7. Available from: http://www.apiindia.org/medicine_update_2013/chap130.pdf. [Last accessed on 2020 Jan 14].

3. Jha V, Garcia-Garcia G, Iseki K, Li Z, Naicker S, Plattner B, et al. Chronic kidney disease: Global dimension and perspectives. Lancet 2013;382:260-72.

4. K/DOQI; National Kidney Foundation. Clinical practice guidelines for anemia of chronic kidney disease. Am J Kidney Dis 2006;47 Suppl 3:S33-53.

5. Modi GK, Jha V. The incidence of end-stage renal disease in India: A population-based study. Kidney Int 2006;70:2131-3.

6. Agarwal SK, Dash SC, Irshad M, Raju S, Singh R, Pandey RM. Prevalence of chronic renal failure in adults in Delhi, India. Nephrol Dial Transplant 2005;20:1638-42.

7. Mani MK. Prevention of chronic renal failure at the community level. Kidney Int Suppl 2003;63:S86-9.

8. Mani MK. Experience with a program for the prevention of chronic renal failure in India. Kidney Int Suppl 2005;67:S75-8.

9. Mani MK. Nephrologist sans frontières: Preventing chronic kidney disease on a shoestring. Kidney Int 2006;70:821-3.

10. CKD Registry of India: Indian Society of Nephrology; 2020. Available from: http://www.ckdri.org. [Last accessed 2020 Apr 30].

11. Astor BC, Muntner P, Levin A, Eustace JA, Coresh J. Association of kidney function with anemia: The third national health and nutrition examination survey (1988-1994). Arch Intern Med 2002;162:1401-8.

12. Kaze FF, Kengne AP, Mambap AT, Halle MP, Mbanya D, Ashuntantang G. Anemia in patients on chronic hemodialysis in Cameroon: Prevalence, characteristics, and management in low resources setting. Afr Health Sci 2015;15:253-60.

13. Babbitt JL, Lin HY. Mechanisms of anemia in CKD. J Am Soc Nephrol 2012;23:1631-4

14. Eschbach JW. The anemia of chronic renal failure: Pathophysiology and the effects of recombinant erythropoietin. Kidney Int 1989;35:134-48.

15. Besarab A, Ayyoub F. In: Schrier RW, editor. Anemia in Renal Disease. 
Diseases of the Kidney and Urinary Tract. $8^{\text {th }}$ ed. Philadelphia, PA: Lippincott Williams and Wilkins; 2007. p. 2406-30.

16. Silverberg DS, Wexler D, Iaina A, Schwartz D. The correction of anemia in patients with the combination of chronic kidney disease and congestive heart failure may prevent the progression of both conditions. Clin Exp Nephrol 2009;13:101-6.

17. Keane WF, Brenner BM, de Zeeuw D, Grunfeld JP, McGill J, Mitch WE, et al. The risk of developing end-stage renal disease in patients with Type 2 diabetes and nephropathy: The renal study. Kidney Int 2003;63:1499-507.

18. Smith RE Jr. The clinical and economic burden of anemia. Am J Manag Care 2010;16:S59-66.

19. Mehdi U, Toto RD. Anemia, diabetes, and chronic kidney disease. Diabetes Care 2009;2:1320-6.

20. Van Nooten FE, Green J, Brown R, Finkelstein FO, Wish J. Burden of illness for patients with non-dialysis chronic kidney disease and anemia in the United States: Review of the literature. J Med Econ 2010;13:241-56

21. Astor BC, Coresh J, Heiss G, Pettitt D, Sarnak MJ. Kidney function and anemia as risk factors for coronary heart disease and mortality: The atherosclerosis risk in communities (ARIC) study. Am Heart J 2006; $151: 492-500$

22. Levey AS, Eckardt KU, Tsukamoto Y, Levin A, Coresh J, Rossert J, et al. Definition and classification of chronic kidney disease: A position statement from kidney disease: Improving global outcomes (KDIGO). Kidney Int 2005;67:2089-100

23. World Health Organization. Hemoglobin concentrations for the diagnosis of anemia and assessment of severity. In: Vitamin and Mineral Nutrition Information System. Geneva: World Health Organization; 2011. Available from: http://www.who.int/vmnis/ indicators/hemoglobin. [Last accessed on $2020 \mathrm{Apr} 30$ ].

24. Kim S, Lim CS, Han DC, Kim GS, Chin HJ, Kim SJ, et al. The prevalence of chronic kidney disease (CKD) and the associated factors to CKD in urban Korea: A population-based cross-sectional epidemiologic study. J Korean Med Sci 2009;24 Suppl 1:S11-21.

25. Lightstone L, Rees AJ, Tomson C, Walls J, Winearls CG, Feehally J. High incidence of end-stage renal disease in Indo-Asians in the UK. QJM 1995;88:191-5.

26. Shastry I, Belurkar S. The spectrum of red blood cell parameters in chronic kidney disease: A study of 300 Cases. J Appl Hematol 2019;10:61-6.

27. Singh NP, Aggarwal L, Singh T, Anuradha S, Kohli R. Anemia, iron studies and erythropoietin in patients of chronic renal failure. J Assoc Physicians India 1999;47:284-90.

28. Poudel B, Yadav BK, Jha B, Raut KB, Pandeya DR. Prevalence and association of anemia with CKD: A hospital based cross-sectional study from Nepal. Biomed Res 2013;24:99-103.

29. Bueno CS, Frizzo MN. Anemia in chronic kidney disease in a hospital in the Northwest region to the state of Rio Grande do Sul. J Bras Nefrol 2014;36:304-14

30. De Francisco AL, Stenvinkel P, Vaulont S. Inflammation and its impact on anemia in chronic kidney disease: From hemoglobin variability to hyporesponsiveness. NDT Plus 2009;2 Suppl 1:i18-26.

31. Elsayed AS, Azab AE. Correlation between chronic kidney diseases and hematological data in Tabatha hospital in Libya. Asian J Pharm Clin Res 2017;10:291-6.

32. Shittu AO, Chijioke A, Biliaminu SA, Makusidi AM, Sanni MA, Abdul-Rahman MB, et al. Hematologic profile of patients with chronic kidney disease in Nigeria. J Nephrol Ren Transplant 2013;5:2-10.

33. Arun S, Prabhu MV, Chowta KN, Bengre ML. The haematological pattern of patients with chronic kidney disease in a tertiary care set up in South India. J Clin Diagn Res 2012;6:1003-6.

34. Suresh M, Reddy NM, Singh MS, Bandi HK, Keerthi GS, Chandrasekhar $\mathrm{M}$, et al. Hematological changes in chronic renal failure. Int J Sci Res Publ 2012;2:1-4

35. Talwar VK, Gupta HL, Shashinarayan. Clinicohaematological profile in chronic renal failure. J Assoc Physicians India 2002;50:228-33. 